\title{
Perceived Clinical Stressors among Saudi Nursing Students
}

\author{
Samantha Ismaile \\ The College of Nursing, Princess Nourah Bint Abdulrahaman University, Riyadh, KSA \\ Email: samantha.ismaile@ymail.com
}

How to cite this paper: Ismaile, S. (2017) Perceived Clinical Stressors among Saudi Nursing Students. Open Journal of Nursing, 7, 463-472.

https://doi.org/10.4236/ojn.2017.74036

Received: March 7, 2017

Accepted: April 14, 2017

Published: April 17, 2017

Copyright $\odot 2017$ by author and Scientific Research Publishing Inc. This work is licensed under the Creative Commons Attribution International License (CC BY 4.0).

http://creativecommons.org/licenses/by/4.0/

\section{(c) (i) Open Access}

\begin{abstract}
Purpose: Nursing profession is considered as a stressful and demanding job. The purpose of this research was to determine stressors types and degrees over two data collection periods in 2015-2016. Methods: This is a quantitative descriptive research study. A purposive sample of 55 female nursing students (complete $4^{\text {th }}$ year cohort) from Princess Nourah University took part in this study. Results: The results highlight that the most influential cause of stress were factors related to taking care of patients, teachers and nursing staff. Moreover, nursing students reported increased level of stress comparing them in two different time periods. Conclusions: To overcome these clinical stressors, it requires students to be equipped with competent knowledge, skills and experience in dealing with the changing needs of patients' condition. Future research should explore nursing students' beliefs and causes of stress and how it can be avoided by conducting a qualitative research study.
\end{abstract}

\section{Keywords}

Stress, Nursing Education, Nursing Student, Clinical Practice, Saudi Arabia

\section{Introduction}

Nursing profession is considered as a stressful and demanding job [1]. Many schoolers reported that nurses face stress in their clinical environment which results in burnout, depression and sleeping disorders [1] [2]. Hence, nursing students need to be prepared in order to face such challenging job. One big challenge for nursing students is to cope with stress associated with training during their clinical placements [3]. Such stress can be defined as a relationship between a person and surrounding environment and it is evaluated by the person own feelings of the situation as being challenging, demanding and outside their available resources [4]. It was reported by many schoolers, that nursing 
students are exposed to stress from clinical placements, and they refer it as "clinical stressors" [3] [5] [6] [7]. Clinical stressors among nursing students can result from many factors namely; initial hospital placements experience, clinical assignments and coursework, nursing skills procedures, assessment and clinical exams, and relationship with patients, families and allied health professionals [3] [5] [6] [7] [8].

\section{Bachelor of Science in Nursing in Saudi Arabia}

Undergraduate students in Saudi Arabia who wish to undertake nursing as a career have to enroll to a 5-year Bachelor of Science in Nursing (BSN) program. This 5-year program consists of 4 academic years in nursing program and one-year internship training program. Each academic year in the nursing program consists of two levels. For example; year one consists of (level 1 and level 2 ), year 2 consists of (level 3 and 4), year 3 consists of (level 5 and 6), year 4 consists of (year 7 and 8), and year 5 consists of level 9 [9]. Nursing students in Saudi Arabia have to undertake both theoretical and clinical requirements during their BSN programme. As each academic year consists of two academic terms, each academic term consists of 17 weeks of study. Theoretical and clinical teaching last up to week 15 and week 16 and exam periods commence in week 17. The number of days spent in the clinical placements varies from one course to another. Despite this, all nursing courses share the same vision for clinical placements. This includes applying a unique nursing process for each individual patient; attending nursing handovers, attending medical rounds, observing and assisting in nursing treatments skills, and keeping records and notes regarding the progress of patients' clinical situation. Clinical assessment for nursing students is done by different ways. This may include; using clinical evaluation sheet to address students' competencies according to the course module, Objective Structure Clinical Examination (OSCE), daily homework's, written case studies and completing clinical handbooks.

According to the literature, nursing students in Saudi Arabia faces stress from their clinical environment's [3] [10] [11]. This negative experience, due to stress, can limit students learning and teaching and affect the overall quality of patient care [12]. The aim of this research study was to determine stressors types, and degrees among nursing students during two clinical periods in their final $\left(4^{\text {th }}\right)$ year of nursing program study. This is an important research study to conduct as it will shed some light on Saudi experience. It will also add more insight about the topic and it will enrich the existing literature.

\section{Aim of the Study and Research Questions}

The aim of the research study was to determine stressors types and degrees during two clinical periods among nursing students in their final $\left(4^{\text {th }}\right)$ year of nursing program study. The research question was as the following:

- What are the clinical stressors degrees and types among nursing undergraduate students at each of the data collection periods in 2015 and 2016 ? 


\section{Methods}

\subsection{Design}

This is a quantitative research study by using a descriptive research design. Data collection took place after students completed their training placements in two times periods in the first and second academic terms of 2015-2016 academic year.

\subsection{Setting}

This study took place at Princess Nourah Bint Abdulrahman University (PNU) in Saudi Arabia. PNU is the largest women's University in the world and is a female only university. The maximum students' capacity is 60,000 students [13]. Data collection took place in the college of nursing.

\subsection{Study Participants}

The study sample included female undergraduate nursing students in their $4^{\text {th }}$ year of the nursing program. The complete year 4 cohort $(n=55)$ in 2015-2016 academic year were invited to participate in this study. A purposeful sampling technique was employed to recruited participants [14]. Therefore there is no need to do power calculation because the complete cohort of year 4 students was included. The first data collection period started between November and December in 2015, and the second data collection took place between April and May in 2016.

\subsection{Instrument}

The study employed a validated questionnaire namely; the perceived stress scale [15]. This questionnaire was translated into Arabic language and published by Alzayyat and AlGamal in 2014 [5]. The Arabic version questionnaire was used as it is the mother tongue language for Saudi nursing students. Permission to use the questionnaires was approved by both original authors.

\subsection{Demographic Data}

Demographic data of nursing students included the following; Age, Academic cumulative score, academic credit hours, marital status employment status, and interest in studying nursing. Hence, all participants were females and speak fluent Arabic as it is the official language in Saudi Arabia.

\subsection{Perceived Stress Scale Questionnaire (Sheu et al., 1997)}

In order to measure stress among nursing students in their clinical placements, perceived stress scale [15] questionnaire were employed. This questionnaire measures both the degrees and types of stressors [15]. The questionnaire is divided into 6 themes with five Likert scale. The scoring numbers ranged from 0 to 116. A low total score indicates lower level of stress and vise versa. The subscale themes are divided as the following; taking care of patients consists of 8 ques- 
tions, stress linked to clinical tutors and staff nurses consists of 6 questions, stress related to coursework and home works consist of 5 questions, stress linked to everyday life and peers consist of 4 questions, stress linked to insufficient clinical knowledge and nursing skills consist of 3 questions, and stress linked to the clinical placemats consist of 3 questions. The total number of questions was 29 questions. Both total scores, and individual subscale scores, were considered. The scoring numbers ranged from 0 to 116. A low total score indicates lower level of stress and vise versa.

\subsection{Ethical Consideration}

Ethical approval was obtained from the PNU-IRB ethics committee before starting the data collection process. Students' responses via questionnaires were maintained anonymous and confidential. An explanation of the research and answering questions session was given prior to signing the consent form. Moreover, information sheets were given to participants. Participants' names and any other personal information were maintained confidential throughout the study. In cases were students felt uncomfortable in filling up the questionnaires, students were advised to discontinue in filling the questionnaire. However, there were no reported cases found during data collection in both periods.

\subsection{Data Analysis}

The Statistical Package for Social Science (SPSS version 22.0; SPSS, Chicago, IL, USA) was used to analysis the gathered data. Descriptive statistics and inferential statistical tests were used. The descriptive statistics used were frequency, percentage, mean, standard deviation, median, minimum and maximum. The paired sample t-test, was used to measure the differences between the results collected in the two different time periods. The normality assumption was checked by using the Shapiro-Wilk (SW) statistical test. All stress variables were normally distributed ( $\mathrm{P}>0.05)$, except of stress from taking care of patients, stress related to teachers and nursing staff. Therefore, the base-10 logarithm transformation was conducted to these variables to obtain more normally-distributed scores.

\section{Results}

\subsection{Demographic Data}

Table 1 shows the characteristics of the study sample. Nursing student mean age was 22.65 years (standard deviation $(\mathrm{SD})=0.77$ ), with a range of $21-25$ years. The academic cumulative score was mean average $3.94(\mathrm{SD}=0.70)$, with a range from $3-5$, half of the students had an average score of $4(n=24,51.1 \%)$, average score of $3(n=13,27.7 \%)$ and an average score of almost $5(n=10,21.3 \%)$. It also shows that 47 of the nursing students were single $(n=47,85.5 \%)$, married $(n=7$, $12.7 \%)$ and just one divorced (1.8\%). In addition, 45 (86.5\%) were interested in studying nursing, while just 7 (13.5\%) were not. Table 1 also shows that, all students had 17 registered credit hours, and they were unemployed. 
Table 1. Demographic data of undergraduate nursing students.

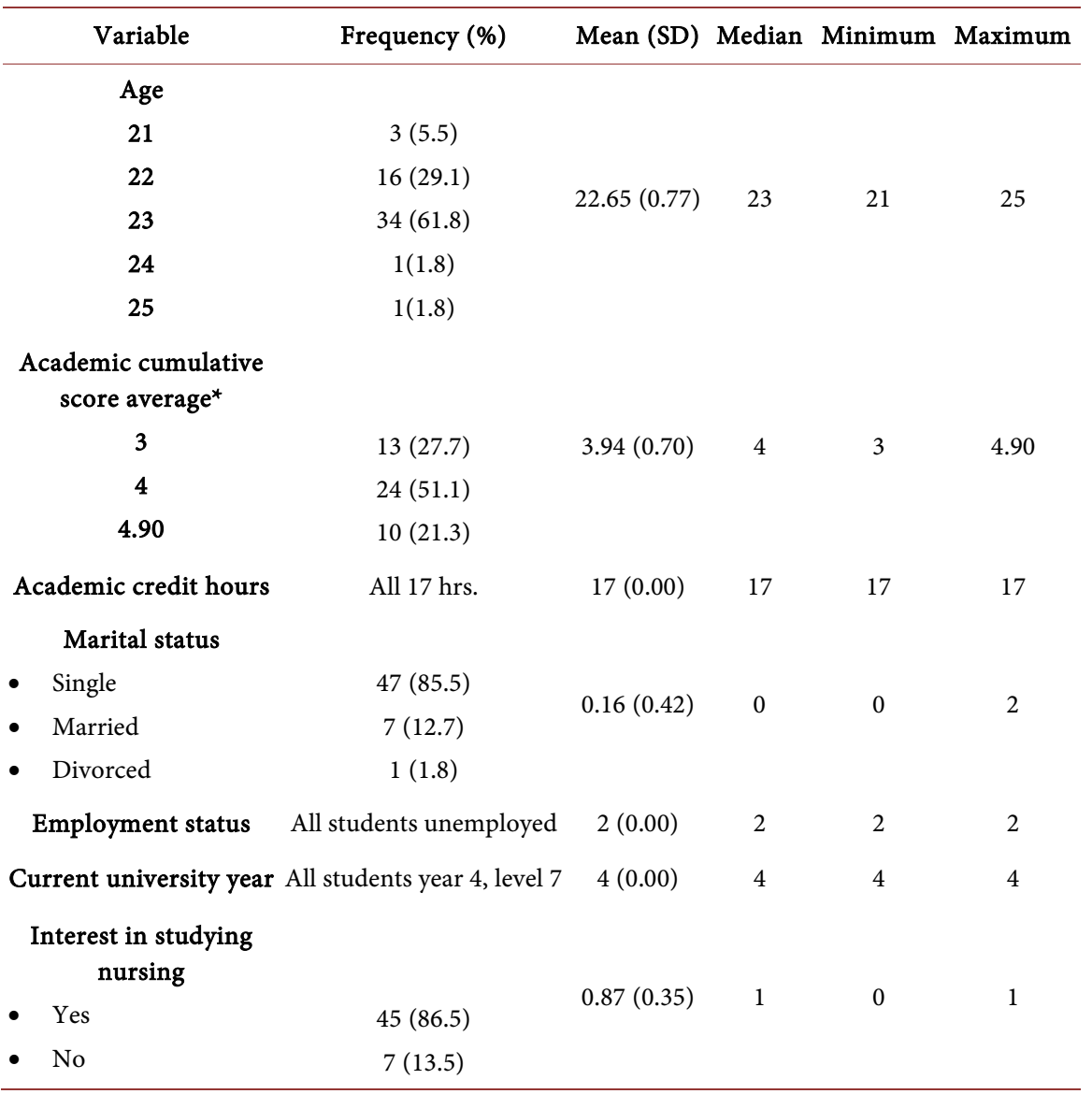

*Academic cumulative score average is equivalent to Grade point average (GPA)

\subsection{Degrees of Perceived Stress and Types of Stressors}

\subsubsection{Stress and Types of Stressors among Level 7 Nursing Students} (Term 1)

According to Table 2, nursing students in their $7^{\text {th }}$ level clinical training scored a range from 20 to 102 (mean $=55.93, \mathrm{SD}=15.37$ ) degrees on the scale of perceived stress. Table 2 shows the subscales results of the perceived stress scale. The results showed that, taking care of patients' subscale (mean $=12.67, \mathrm{SD}=$ 4.60 ), the stress related to teachers and nursing staff subscale (mean $=12.82, \mathrm{SD}$ $=4.15)$, the stress from assignments and workloads subscale (mean $=11.95, \mathrm{SD}$ = 3.67), the stress from peers and daily life subscale (mean $=7.56, \mathrm{SD}=2.89$ ), the stress from lack of professional knowledge and skills subscale (mean $=5.05$, $\mathrm{SD}=2.10)$ and the stress from the clinical environment subscale (mean $=5.87$, $\mathrm{SD}=2.49$ ). It also shows the ranking of the subscales of the perceived stress and the stress from teachers and nursing staff stress was the highest and lack of professional knowledge and skills stress was the lowest.

\subsubsection{Stress and Types of Stressors among Level 8 Nursing Students} (Term 2)

According to Table 2, nursing students in their $8^{\text {th }}$ level reported that their degrees of perceived stress in clinical placements period ranged from 38 to 87 
Table 2. Perceived stress among nursing students during clinical placements $(n=55)$.

\begin{tabular}{cccccccc}
\hline & \multicolumn{3}{c}{ Level 7/year 4 (Term 1) } & \multicolumn{3}{c}{ Level 8/year 4 (Term 2) } \\
\hline Subscale & Ranking & Mean & SD & Ranking & Mean & SD \\
\hline Taking care of patients & 2 & 12.67 & 4.60 & 1 & 14.55 & 3.36 \\
Teachers and nursing staff & 1 & 12.82 & 4.15 & 2 & 13.82 & 4.06 \\
Assignments and workloads & 3 & 11.95 & 3.67 & 3 & 12.16 & 3.57 \\
Peers and daily life & 4 & 7.56 & 2.89 & 4 & 9.09 & 4.62 \\
Clinical environment & 5 & 5.87 & 2.49 & 5 & 6.31 & 2.84 \\
Lack of professional knowledge and skills & 6 & 5.05 & 2.10 & 6 & 4.73 & 2.16 \\
\hline
\end{tabular}

(mean $=60.55, \mathrm{SD}=12.23)$. The results showed that, taking care of patients' subscale (mean $=14.55, \mathrm{SD}=3.36)$, stress related to teachers and nursing staff subscale (mean = $13.82, \mathrm{SD}=4.06$ ), and stress from assignments and workloads subscale ( $m e a n=12.16$, $\mathrm{SD}=3.57$ ). Moreover, stress from peers and daily life subscale (mean $=9.09, \mathrm{SD}=$ 4.62), stress from lack of professional knowledge and skills subscale (mean $=4.73, \mathrm{SD}=$ 2.16 ) and stress from the clinical environment subscale (mean $=6.31, \mathrm{SD}=2.84$ ). Table 2 shows that taking care of patients was the highest source of stress and lack of professional knowledge and skills was the lowest stress source.

\subsection{Differences in the Perceived Stress Degrees and Types}

Using paired t-test analysis, the results revealed that the mean of the total perceived stress scale and the six perceived stress subscale scores were higher among students in level 8 clinical placements than in level 7 clinical placements. The results showed that there was no statistically-significant difference at the level of 0.05 in the total perceived stress scale score and all subscales scores among nursing students in level 7 and level 8 clinical periods except for taking care of patients' subscale and clinical environment subscale see Table 3 .

\section{Discussion}

\subsection{Clinical Stressors among Undergraduate Students}

According to the results, the most perceived stress among undergraduate nurses in level 7 were stress related to teachers and nursing staff followed by stress from taking care of patients. While in level 8 , the most perceived stress among undergraduate nurses were stress from taking care of patients followed by stress related to teachers and nursing staff. A possible explanation on students switching form ranking teachers and nursing staff as the highest source of stressors to stress from taking care of patients in both data collection periods is that students were getting more involved in patient care. This requires students to have competent knowledge, skills and experience in dealing with the changing needs of patients' condition. When student nurses lack these competencies whether because of unclear clinical guidelines and policies or even lack of knowledge, skills and experience, students suffer from stress. Indeed, this is the responsibility of the clinical teachers and educators to asses' students' competencies and readi- 
Table 3. Comparing nursing students' perceived stress scores using paired t-test statistics.

\begin{tabular}{|c|c|c|c|c|}
\hline Scale/Subscale & $\operatorname{Mean}(\mathrm{SD})$ & $\mathrm{T}$ & d.f & P-value \\
\hline \multicolumn{5}{|l|}{ Total Perceived Stress Scale } \\
\hline - Pre & $55.93(15.37)$ & $-1.59-$ & 54 & 0.12 \\
\hline - Post & $60.55(12.23)$ & & & \\
\hline \multicolumn{5}{|l|}{ Taking care of patient's subscale } \\
\hline - Pre & $12.67(4.60)$ & $-2.35-$ & 54 & $0.02^{*}$ \\
\hline - Post & $14.55(3.36)$ & & & \\
\hline \multicolumn{5}{|l|}{ Teachers and nursing staff subscale } \\
\hline - Pre & $12.82(4.15)$ & $-1.19-$ & 54 & 0.24 \\
\hline - Post & $13.82(4.06)$ & & & \\
\hline \multicolumn{5}{|c|}{ Lack of professional knowledge and skills subscale } \\
\hline - Pre & $11.95(3.67)$ & $-0.29-$ & 54 & 0.78 \\
\hline - Post & $12.16(3.57)$ & & & \\
\hline \multicolumn{5}{|l|}{ Clinical environment subscale } \\
\hline - Pre & $7.56(2.89)$ & $-2.12-$ & 54 & $0.04^{*}$ \\
\hline - Post & $9.09(4.62)$ & & & \\
\hline \multicolumn{5}{|l|}{ Assignments and workloads subscale } \\
\hline - Pre & $5.05(2.10)$ & 0.86 & 54 & 0.39 \\
\hline - Post & $4.73(2.16)$ & & & \\
\hline \multicolumn{5}{|l|}{ Peers and daily life subscale } \\
\hline - Pre & $5.83(2.49)$ & $-0.96-$ & 53 & 0.34 \\
\hline - Post & $6.31(2.84)$ & & & \\
\hline
\end{tabular}

ness to cope with challenging clinical situations. One solution of this is the implementation of simulation in undergraduate teaching and learning. Simulation teaching is an effective teaching method to improve students' competencies, skills and knowledge for learning patient quality of care and safety [16]. This result was consistent with other studies [2] [5] [17] that reported stress for patient care was the most influential factor for stress among undergraduate students.

Also, undergraduate nurses reported high level of stress caused by the nursing staff and teachers. This result was similar to Alzayyat and AlGamal results in 2014 [5]. It seems like students'-teachers' relationship is an influential contributing factor for stress. This can be due to the unclear expectations between teachers and students. Indeed, it is the responsibility of the teachers to set out a clear, defined and well establish learning outcomes, objectives and goals for any clinical placement. This will avoid teachers to have negative expectation of their students, and thus causes stress for students. Moreover, the relationship of nursing staff and students were reported as a high source of stress and it had students to have a negative experience of belongingness in their clinical learning setting [18]. Staff nurses who are uncooperative, unwilling to help and unsupported causes students to be stressed. Again, it is the responsibility of clinical teacher to improve students- staff nurses' relationship by employing different strategies. For example; improve communication channels between the univer- 
sity and hospital and the implementation of preceptor education program before starting the clinical placements of nursing students.

Despite these differences in ranking the most perceived stress, students ranking in assignments and workloads, peers and daily life, clinical environment and lack of professional knowledge and skills were consistent in both periods. These results were similar to [2] [5] [17]. In this study, the amount of overloaded coursework's, completing clinical log books and assignments given to students were ranked as one of the top sources of stress.

In summary, program directors, course coordinators, and clinical teachers have a great responsibility in creating a stress free environment for their students. This is done by providing students with a well established foundation of knowledge, nursing skills, ethics and values. This will ensure on providing an effective clinical learning experience and hence its effect on the overall patient quality of care and safety.

\subsection{Differences in the Perceived Stress Degrees}

In this study, nursing students reported increased level of stress comparing them in two different time periods. The increase level of stress indicates that students were not coping well in their clinical placements. This will have a negative clinical learning experience on students. The increase level of stress with the progress level of undergraduate nursing program was also reported by Alzayyat and AlGamal [8]. Again, it is the program director, course coordinator and clinical teacher responsibility to reduce the contributing factors which causes stress among nursing student in clinical placements. There are many strategies to overcome this. For example; improving nursing program by getting students and clinical instructors feedback and expectations, improve clinical teaching by employing simulation, set a clear and well defined learning objectives for each clinical day and finally improve communication channels between the university and the hospital setting.

\section{Conclusion}

This descriptive research study identifies types and degrees of clinical stressors among Saudi nursing students. The result highlights that the most cause of stress from the clinical practice were factors related to taking care of patients, teachers and nursing staff and assignments and workloads. Making use of the results regarding identifying types and degrees of clinical stressors among undergraduate nursing, the nursing clinical instructors, course coordinators, and program directors can take action to reduce level of stress. This can be done by preparing students with knowledge, skills, and experience needed in clinical practice settings, also, reviewing the nursing program and training clinical instructors. It is recommended to do more research on nursing student competencies before starting the clinical placements. This will help in addressing their needs and equipping them with all needed knowledge and skills before starting their clinical placements. 


\section{Limitations}

The study sample included purposive sampling technique which has its limitations. This may include some students being absent and not participating in completing the questionnaire. This could have some impact on students' response which in turn may slightly change the results.

It is recommended to have a qualitative study which may shed some light into students deep feelingly and intentions regarding clinical stressors.

\section{References}

[1] Watson, R., Deary, I., Thompson, D. and Li, G. (2008) A Study of Stress and Burnout in Nursing Students in Hong Kong: A Questionnaire Survey. International Journal of Nursing Studies, 45, 1534-1542. https://doi.org/10.1016/j.ijnurstu.2007.11.003

[2] Por, J. (2005) A Pilot Data Collecting Exercise on Stress and Nursing Students. British Journal of Nursing, 14, 1180-1185. https://doi.org/10.12968/bjon.2005.14.22.20169

[3] Ismaile, S. (2016) Stressors' and Coping Strategies among Saudi Nursing Students' in Their Clinical Practice. HealthMed Journal, 10, 25-32.

[4] Lazarus, R.S. and Folkman, S. (1984) Stress, Appraisal, and Coping. Springer Publishing Company, Berlin.

[5] Al-Zayyat, A.S. and Al-Gamal, E. (2014) Perceived Stress and Coping Strategies among Jordanian Nursing Students during Clinical Practice in Psychiatric/Mental Health Courses. International Journal of Mental Health Nursing, 23, 326-335. https://doi.org/10.1111/inm.12054

[6] McKenna, L. and Plummer, V. (2013) Indonesian Student Nurses' Perceptions of Stress in Clinical Learning: A Phenomenological Study. Journal of Nursing Education and Practice, 3, 56-65.

[7] Ewashen, C. and Lane, A. (2007) Pedagogy, Power and Practice Ethics: Clinical Teaching in Psychiatric/Mental Health Settings. Nursing Inquiry, 14, 255-262. https://doi.org/10.1111/j.1440-1800.2007.00374.x

[8] Suen, W.Q., Lim, S., Wang, W. and Kowitlawakul, Y. (2016) Stressors and Expectations of Undergraduate Nursing Students during Clinical Practice in Singapore. International Journal of Nursing Practice, 22, 574-583.

https://doi.org/10.1111/ijn.12473

[9] Ismaile, S., Alsahlia, H., Khan, S. and Alshehri, H. (2016) Mix Research Methods: Teaching and Learning in 2nd Year Bachelor Nursing Program. International Journal of Advanced Nursing Studies, 5, 127-131. https://doi.org/10.14419/ijans.v5i2.6340

[10] Eswi, A., Radi, S. and Youssri, H. (2013) Stress/stressors as Perceived by Baccalaureate Saudi Nursing Students. Middle-East Journal of Scientific Research, 14, 193202.

[11] El-Gilany, A., Amr, M. and Hammad, S. (2008) Perceived Stress among Male Medical Students in Egypt and Saudi Arabia: Effect of Sociodemographic Factors. Annals of Saudi Medicine, 28, 442-448. https://doi.org/10.4103/0256-4947.51666

[12] Ismaile, S. (2015) Nursing Studies: Factors Promoting and Inhibiting Adherence to Clinical Practice Guidelines among the Nursing Profession. Durham University, Durham, UK.

[13] Princess Nourah University. About Princess Nourah University 2017. 
http://www.pnu.edu.sa/arr/Pages/default.aspx

[14] Tongco, M.D.C. (2007) Purposive Sampling as a Tool for Informant Selection. Ethnobotany Research \& Applications, 5, 147-158.

[15] Sheu, S., Lin, H., Hwang, S., Yu, P., Hu, W. and Lou, M. (1997) The Development and Testing of Perceived Stress Scale of Clinical Practice. Nursing Research (Republic of China), 5, 341-351.

[16] Reime, M., Johnsgaard, T., Kvam, F., Aarflot, M., Breivik, M., Engeberg, J., et al. (2016) Simulated Settings; Powerful Arenas for Learning Patient Safety Practices and Facilitating Transference to Clinical Practice. A Mixed Method Study. Nurse Education in Practice, 21, 75-82. https://doi.org/10.1016/j.nepr.2016.10.003

[17] Chen, Y.-W. and Hung, C.-H. (2014) Predictors of Taiwanese Baccalaureate Nursing Students' Physio-Psycho-Social Responses during Clinical Practicum. Nurse Education Today, 34, 73-77. https://doi.org/10.1016/j.nedt.2013.02.021

[18] Levett-Jones, T., Lathlean, J., Higgins, I. and McMillan, M. (2009) Staff-Student Relationships and Their Impact on Nursing Students' Belongingness and Learning. Journal of Advanced Nursing, 65, 316-324. https://doi.org/10.1111/j.1365-2648.2008.04865.x

Submit or recommend next manuscript to SCIRP and we will provide best service for you:

Accepting pre-submission inquiries through Email, Facebook, LinkedIn, Twitter, etc. A wide selection of journals (inclusive of 9 subjects, more than 200 journals)

Providing 24-hour high-quality service

User-friendly online submission system

Fair and swift peer-review system

Efficient typesetting and proofreading procedure

Display of the result of downloads and visits, as well as the number of cited articles Maximum dissemination of your research work

Submit your manuscript at: http://papersubmission.scirp.org/

Or contact ojn@scirp.org 